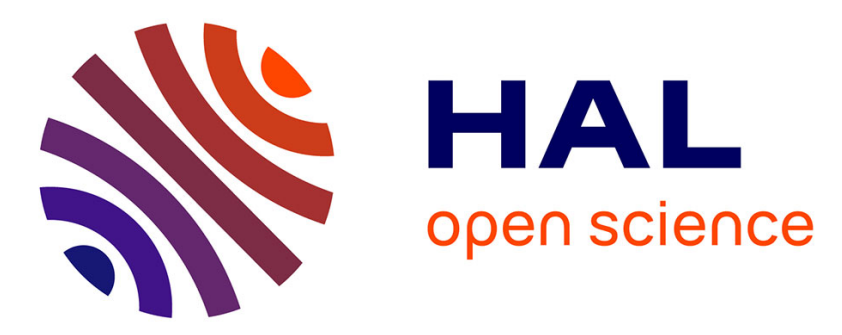

\title{
Crystallization of Ge2Sb2Te5 nanometric phase change material clusters made by gas-phase condensation
}

G. Ghezzi, Robert Morel, A. Brenac, Nathalie Boudet, M. Audier, F. Fillot, S. Maîtrejean, Francoise Hippert

\section{- To cite this version:}

G. Ghezzi, Robert Morel, A. Brenac, Nathalie Boudet, M. Audier, et al.. Crystallization of Ge2Sb2Te5 nanometric phase change material clusters made by gas-phase condensation. Applied Physics Letters, 2012, 101, pp.233113. 10.1063/1.4769435 . hal-00989954

\section{HAL Id: hal-00989954 https://hal.science/hal-00989954}

Submitted on 12 May 2014

HAL is a multi-disciplinary open access archive for the deposit and dissemination of scientific research documents, whether they are published or not. The documents may come from teaching and research institutions in France or abroad, or from public or private research centers.
L'archive ouverte pluridisciplinaire HAL, est destinée au dépôt et à la diffusion de documents scientifiques de niveau recherche, publiés ou non, émanant des établissements d'enseignement et de recherche français ou étrangers, des laboratoires publics ou privés. 


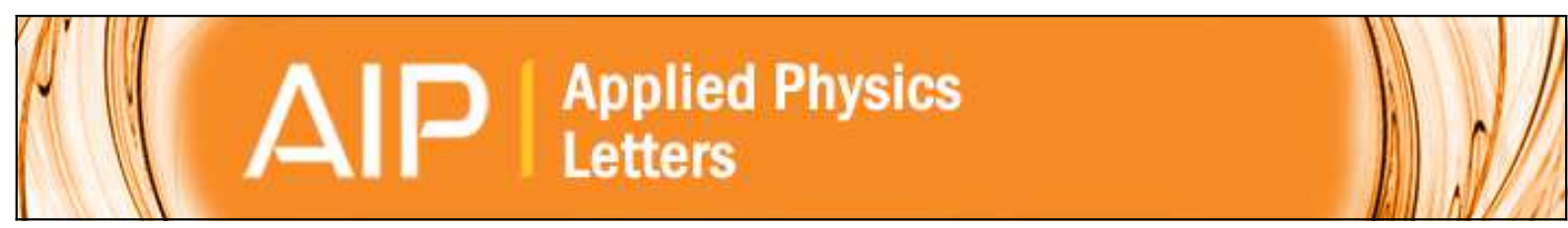

\section{Crystallization of Ge2Sb2Te5 nanometric phase change material clusters made by gas- phase condensation}

G. E. Ghezzi, R. Morel, A. Brenac, N. Boudet, M. Audier, F. Fillot, S. Maitrejean, and F. Hippert

Citation: Applied Physics Letters 101, 233113 (2012); doi: 10.1063/1.4769435

View online: http://dx.doi.org/10.1063/1.4769435

View Table of Contents: http://scitation.aip.org/content/aip/journal/apl/101/23?ver=pdfcov

Published by the AIP Publishing

\section{Articles you may be interested in}

Nanoscale nuclei in phase change materials: Origin of different crystallization mechanisms of Ge2Sb2Te5 and AglnSbTe

J. Appl. Phys. 115, 063506 (2014); 10.1063/1.4865295

Phase change behaviors of Zn-doped Ge2Sb2Te5 films

Appl. Phys. Lett. 101, 051906 (2012); 10.1063/1.4742144

Ge2Sb2Te5 phase-change films on polyimide substrates by pulsed laser deposition

Appl. Phys. Lett. 101, 031905 (2012); 10.1063/1.4737410

Observation and modeling of polycrystalline grain formation in Ge2Sb2Te5

J. Appl. Phys. 111, 104308 (2012); 10.1063/1.4718574

Multi-level phase change memory devices with Ge2Sb2Te5 layers separated by a thermal insulating Ta2O5 barrier layer

J. Appl. Phys. 110, 124517 (2011); 10.1063/1.3672448

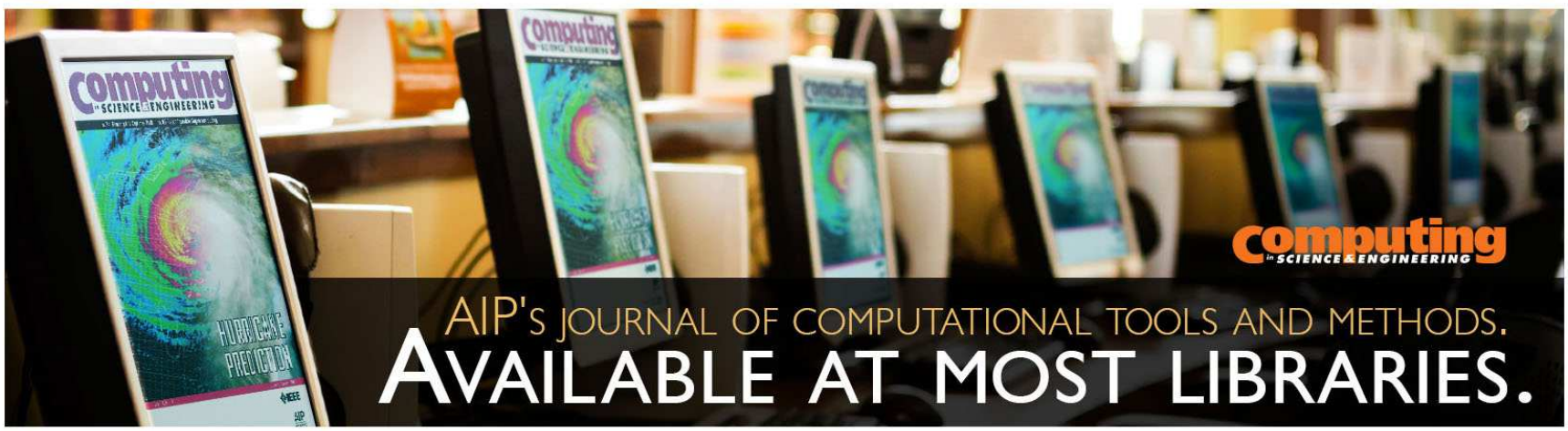




\title{
Crystallization of $\mathrm{Ge}_{2} \mathrm{Sb}_{2} \mathrm{Te}_{5}$ nanometric phase change material clusters made by gas-phase condensation
}

\author{
G. E. Ghezzi ${ }^{1,2}$ R. Morel, ${ }^{3}$ A. Brenac, ${ }^{3}$ N. Boudet,${ }^{4}$ M. Audier,${ }^{2}$ F. Fillot,${ }^{1}$ S. Maitrejean, ${ }^{1}$ \\ and F. Hippert ${ }^{2,5}$ \\ ${ }^{1}$ CEA Leti, Minatec campus, 17 Rue des Martyrs, 38054 Grenoble, France \\ ${ }^{2}$ LMGP (CNRS, Grenoble INP-Minatec), 3 parvis Louis Néel, 38016 Grenoble, France \\ ${ }^{3}$ INAC/SP2M and Université Joseph Fourier, CEA Grenoble, 38054 Grenoble, France \\ ${ }^{4}$ Institut Néel, CNRS-UJF, 25 rue des Martyrs, BP 166, 38042 Grenoble, France \\ ${ }^{5}$ LNCMI (CNRS-UJF-UPS-INSA), 25 rue des Martyrs, BP 166, 38042 Grenoble, France
}

(Received 18 July 2012; accepted 15 November 2012; published online 6 December 2012)

The crystallization behavior of $\mathrm{Ge}_{2} \mathrm{Sb}_{2} \mathrm{Te}_{5}$ nanometric clusters was studied using X-ray diffraction with in situ annealing. Clusters were made using a sputtering gas-phase condensation source, which allowed for the growth of well-defined, contaminant-free, and isolated clusters. The average size for the clusters is $5.7 \pm 1 \mathrm{~nm}$. As-deposited amorphous clusters crystallize in the fcc cubic phase at $180^{\circ} \mathrm{C}$, while for thin films, the phase change temperature is $155^{\circ} \mathrm{C}$. This observation illustrates the scalability of the $\mathrm{Ge}_{2} \mathrm{Sb}_{2} \mathrm{Te}_{5}$ phase change from the amorphous to the cubic state in three-dimensionally confined systems in this size range. (C) 2012 American Institute of Physics. [http://dx.doi.org/10.1063/1.4769435]

Phase change materials (PCM) such as $\mathrm{Ge}_{2} \mathrm{Sb}_{2} \mathrm{Te}_{5}$ (GST) display unique properties that allowed for the development of optical storage media, and are also good candidates for application in non-volatile memory (phase change random access memory (PCRAM)). ${ }^{1}$ Viable PCRAM applications call for bit volume much smaller than that of optical media and this size reduction opens a number of questions regarding the scalability of PCM, for instance, the size dependence of the crystallization temperature $T_{\mathrm{x}}$.

In this paper, the use of a sputtering gas-aggregation method for the growth of GST nanometric clusters has allowed the study of the phase transformation in isolated amorphous particles. The crystallization of those clusters is definitely observed and their crystallization temperature is close to that of the bulk material, which is a surprising result for such small particles. The presence of strain in the crystalline clusters has been observed. These two features-low $T_{\mathrm{x}}$ and strain —challenge the assumption that the stress state has a strong impact on the crystallization temperature in lowdimension phase change materials. ${ }^{2}$

Many studies regarding the scalability of the PCM deal with the thickness dependence of the amorphous to fcc crystalline phase transition in GST thin films. ${ }^{2-5}$ The transition temperature is similar to that of the bulk-close to $155^{\circ} \mathrm{C}-$ for all films with thicknesses above $10 \mathrm{~nm}$. Below that, the increase in $T_{\mathrm{x}}$ differs from one study to the other: The largest reported value is for $2 \mathrm{~nm}$ GST thin films deposited on $\mathrm{Si}$ and covered with $\mathrm{Al}_{2} \mathrm{O}_{3}$, with $T_{\mathrm{x}}=380^{\circ} \mathrm{C},{ }^{3}$ while only small changes in $T_{\mathrm{x}}$ are measured for GST films sandwiched by $\mathrm{ZnS}-\mathrm{SiO}_{2}{ }^{2,5}$ These studies illustrate that the cladding material plays a significant role in the thickness dependence of the phase transition. ${ }^{2,6}$ In phase change materials where the phase transition is nucleation-dominated, two mechanisms have been proposed regarding this effect. The first one considers that a strong interface interaction between the PCM and the cladding material impedes the nucleation of crystallites within the layer. ${ }^{7}$ The second one considers a correlation between the mechanical stress state induced by the cladding material, and the change in $T_{\mathrm{x}} \cdot{ }^{2}$ One difficulty with this approach is that, even in the case where the stress in the cladding layer is known, the evaluation of the level of strain induced in the embedded layer is delicate. ${ }^{8}$ In all cases, due to the $3 \mathrm{D}$ confinement, clusters are the ideal system for assessing the size effects that could alter the phase change properties. On one hand, the interface effects are enhanced due to a larger surface/volume ratio and, on the other hand, for isolated clusters in a matrix the plastic relaxation is limited due to the confinement, which can thus affect strain state of the PCM.

Some results with GST nanoclusters have been reported. For nanoclusters made by electron beam lithography with size above $20 \mathrm{~nm}$, no significant change in $T_{\mathrm{x}}$ has been observed $^{9}$ while $15 \mathrm{~nm}$ nanoclusters obtained with diblock copolymer transform directly into the hexagonal phase. ${ }^{10}$ The growth of GST clusters using laser ablation has been reported, with discrepancies in the reported crystallization behavior. ${ }^{11-13}$ The first results ${ }^{11}$ indicate that, for $15 \mathrm{~nm}$ sizeselected clusters, amorphous particles with irregular shape are obtained when the annealing is below $200{ }^{\circ} \mathrm{C}$, a mixture of hexagonal and fcc phases is observed when the annealing is above $300^{\circ} \mathrm{C}$, whereas the pure fcc phase is observed when annealing is performed above $400^{\circ} \mathrm{C}$. A second report indicates clusters with a mixture of amorphous and fcc phase for all temperatures, ${ }^{12}$ while a third one indicates mostly amorphous as-prepared particles transforming into a mixture of hexagonal and fcc phases at $100^{\circ} \mathrm{C}$, and in a mostly fcc phase at $200{ }^{\circ} \mathrm{C} .{ }^{13}$ The main conclusion from these studies is that both the cubic fcc and amorphous phases can be observed in nanometric GST clusters. On the other hand, the observation of an unambiguous phase transition from an amorphous to a crystalline structure, at a definite temperature, has not yet been achieved. Moreover, in these studies, the effect of the cladding material on the phase change properties of clusters has not been addressed. 
In this paper, we present measurements of the crystallization of GST nanometric clusters with average size $5.7 \pm 1 \mathrm{~nm}$, embedded in alumina, and $10 \mathrm{~nm}$ GST thin films sandwiched with alumina. Clusters and thin films are prepared in a UHV chamber with a sputtering-gas phase condensation cluster source, which allows for the growth of contaminant-free and isolated ternary particles, and two additional standard sputtering guns for the deposition of GST and alumina thin films. ${ }^{14}$ The cluster source consists in a magnetron sputtering head inserted in a liquid nitrogen cooled tube: $\mathrm{A} \mathrm{Ge}_{2} \mathrm{Sb}_{2} \mathrm{Te}_{5}$ solid target is DC sputtered in a 0.1 mbar cold argon gas, which makes the sputtered atoms condensate into nanometer-sized clusters as they drift along the gas flow lines in the source. Clusters are expelled through an iris diaphragm in the vacuum, forming a beam which is directed onto the sample in a deposition chamber next to the cluster source. DC magnetron is used for the sputtering of GST thin films (using the same sputtering target as the one used for clusters) and RF magnetron is used for $\mathrm{Al}_{2} \mathrm{O}_{3}$. All depositions are made at room temperature. Average cluster size measured with a time of flight mass spectrometer is $5.7 \pm 1 \mathrm{~nm}$ at half maximum. Clusters morphology was controlled by TEM microscopy: A low density layer of clusters was deposited on copper grids coated with holey carbon films, covered with $1 \mathrm{~nm} \mathrm{Al}_{2} \mathrm{O}_{3}$. The distribution of clusters on the surface is random. No atomic planes are visible for the clusters and the contrast is similar for all particles, which is an indication that as-deposited clusters are amorphous, as confirmed by X-ray analysis. ${ }^{23}$ GST thin films and clusters compositions were measured with Rutherford backscattering spectrometry and particle-induced X-ray emission. Thin films content is Ge:Sb:Te $=23: 24: 53( \pm 3)$, very close to the $\mathrm{Ge}_{2} \mathrm{Sb}_{2} \mathrm{Te}_{5}=22: 22: 56$ targeted composition, and clusters composition is 28:27:45 $( \pm 3)$, indicating that the GST clusters are slightly Te depleted, as often reported for GST clusters or thin films, ${ }^{3,9,12,15}$ while the GST sputtered thin films are very close to the nominal $\mathrm{Ge}_{2} \mathrm{Sb}_{2} \mathrm{Te}_{5}$ stoichiometry. Within experimental resolution, the GST clusters composition is identical before and after annealing.

Two types of samples were prepared on $\mathrm{Si}$ substrates: The first one consists in $10 \mathrm{~nm} \mathrm{Al}_{2} \mathrm{O}_{3} / 10 \mathrm{~nm}$ GST thin film/ $10 \mathrm{~nm} \mathrm{Al}_{2} \mathrm{O}_{3}$, the second one consists in GST clusters multilayer with the following structure: $6 \mathrm{~nm} \mathrm{Al}_{2} \mathrm{O}_{3} /(\mathrm{GST}$ clusters layer with $0.07 \mathrm{ML}$ of particles $\left./ 3 \mathrm{~nm} \mathrm{Al}_{2} \mathrm{O}_{3}\right) \times 4 / 3 \mathrm{~nm} \mathrm{Al}_{2} \mathrm{O}_{3}$. This later structure-with an average distance between clusters of $15 \mathrm{~nm}$-was chosen to avoid sintering effects during annealing. A $20 \mathrm{~nm} \mathrm{Al}_{2} \mathrm{O}_{3}$ thin film was also grown for background subtraction in the $\mathrm{X}$-ray experiments.
A first set of clusters and thin film samples was annealed under vacuum at $200^{\circ} \mathrm{C}$, hereafter referred to as ex situ samples. Temperature was ramped at $10^{\circ} \mathrm{C} / \mathrm{min}$, held at $200^{\circ} \mathrm{C}$ for $30 \mathrm{~min}$, and ramped down to ambient temperature. X-ray diffraction measurements $(\lambda=0.69654 \AA)$ using synchrotron radiation on the BM02 CRG-D2AM beamline (ESRF Grenoble, France) were performed at room temperature on both the ex situ and as deposited samples. The spectra were recorded in a reflection geometry with a $4^{\circ}$ angle of incidence for the incoming X rays, by means of a $2 \mathrm{D}$ CCD detector allowing for a $2 \theta$ range between $8^{\circ}$ and $26^{\circ}$. For a second set of clusters and thin film samples (in situ samples), X-ray diffraction spectra were recorded as a function of the temperature during the annealing, using a domed oven stage. Temperature was increased in $10^{\circ} \mathrm{C}$ steps after which spectra were recorded for $26 \mathrm{~min}$. In all cases, the $\mathrm{Al}_{2} \mathrm{O}_{3}$ blank sample signal, measured in similar conditions, was subtracted to remove the large background from the Si substrate.

The angular integrated intensity from the $2 \mathrm{D}$ images ${ }^{23}$ is shown in Figure 1. For the as-deposited film, the two broad maxima at $2 \theta=12.9^{\circ}$ and $21.6^{\circ}$ allow to conclude to an amorphous state. Their positions match the first two maxima in the reported GST amorphous structure factor. ${ }^{16}$ For the annealed film, Bragg peaks are observed. Their positions can be indexed as a fcc cubic structure. The fcc out of plane lattice parameter ${ }^{17}$ is $0.601 \pm 0.001 \mathrm{~nm}$ that closely matches the lattice parameter reported for bulk GST, $0.60117(5) \mathrm{nm} .{ }^{18}$ Due to the existence of a texture (see the $2 \mathrm{D}$ image in supplementary material), the relative intensity for the peaks is not the one expected for a powder pattern. With as-deposited clusters, the X-ray diffraction spectra show no Bragg peaks. For the $200{ }^{\circ} \mathrm{C}$ annealed clusters, one clearly detects the (200) and (220) diffraction Bragg peaks which are the two most intense reflections expected in a powder diffraction pattern from the bulk fcc phase. Indeed, the 2D images are isotropic, indicating the absence of texture in clusters. As expected, due to the smaller crystallite size, the peaks width for the clusters is larger than for the thin film. Besides, a clear shift of the diffraction lines with respect to the bulk position is observed. The fcc out of plane lattice parameter for the crystalline clusters calculated from the (200) and (220) peaks position is $0.611 \mathrm{~nm} \pm 0.002$, that is $1.7 \%$ larger than for the crystallized $10 \mathrm{~nm}$ thin film.

In order to determine $T_{\mathrm{x}}$, X-ray diffraction spectra for as-deposited clusters and thin films samples were recorded as a function of the temperature, with in situ annealing. The change in the thin film (220) diffraction peak from $150^{\circ} \mathrm{C}$ to
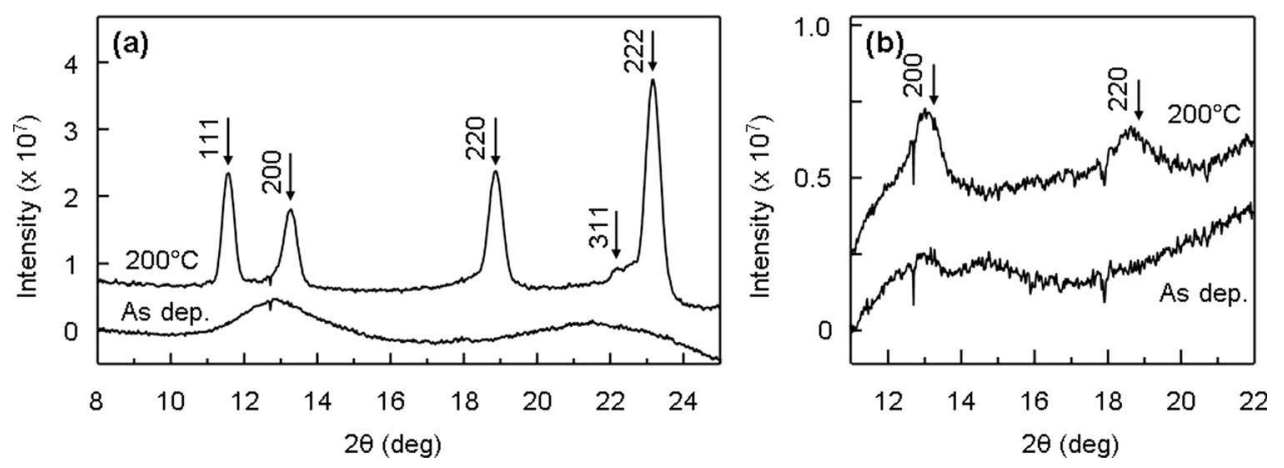

FIG. 1. X-ray diffraction spectra for (a) as-deposited and $200^{\circ} \mathrm{C}$ ex situ annealed GST film and (b) clusters. Arrows in (a) and (b) indicate bulk GST fcc peaks position. Curves are shifted for clarity. 

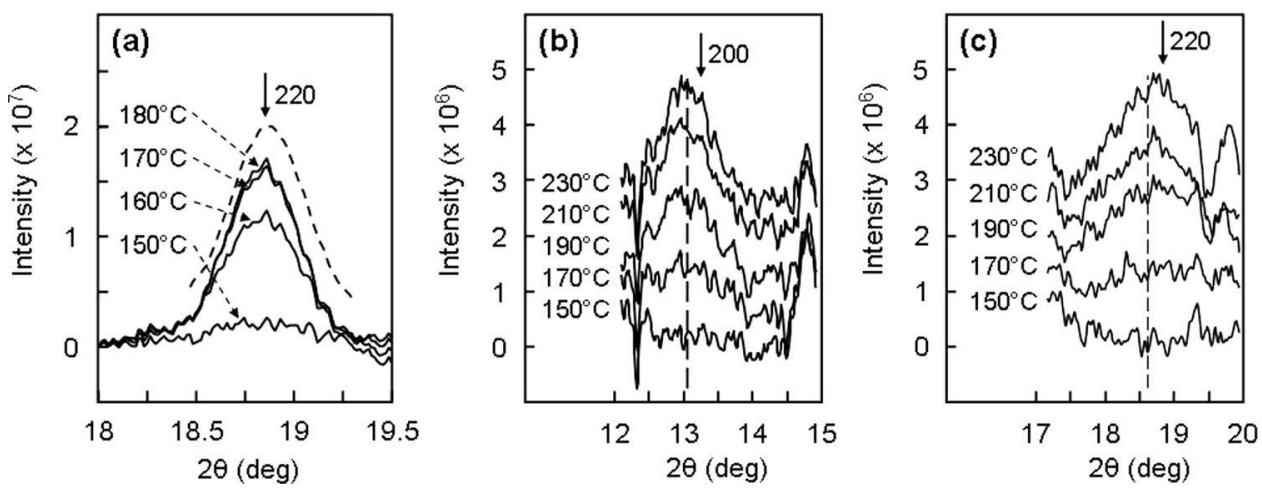

FIG. 2. (a) In situ annealed GST thin film (220) diffraction peak at different temperatures. Dotted line is the $200^{\circ} \mathrm{C}$ ex situ annealed thin film peak, measured at room temperature. Arrow indicates the bulk GST peak position. In situ annealed GST clusters (200) diffraction peak (b) and (220) diffraction peak (c) at different temperatures. In (b) and (c), curves are evenly shifted to ease viewing, arrows indicate the bulk GST peak position, and dotted lines indicate the $200^{\circ} \mathrm{C}$ ex situ annealed clusters peak positions, measured at room temperature. $180^{\circ} \mathrm{C}$ is plotted in Figure 2(a). Although the oven dome significantly decreases the signal to noise ratio, the peak intensity at $180^{\circ} \mathrm{C}$ is comparable with that of the ex situ annealed sample. At $150^{\circ} \mathrm{C}$, no signal is recorded above background level, while at $170^{\circ} \mathrm{C}$, the peak is close to its final amplitude. It can be observed that the (220) peak position at $180^{\circ} \mathrm{C}$ is slightly below that of the ex situ annealed thin film measured at room temperature, which can be explained by the GST thermal dilatation. ${ }^{19}$ The (200) and (220) diffraction peaks for in situ annealed clusters are shown in Figures 2(b) and 2(c). Despite the high noise level and spurious background contribution, the parallel rise in the amplitude for the two peaks is visible.

The crystallization temperature is obtained from the rise in the integrated intensity for the in situ annealed thin film and clusters (Figure 3) as the midpoint of the rise step. For the thin film, the rise is almost parallel for the (111) and the (220) peaks. $T_{\mathrm{x}}$ is equal to $155^{\circ} \mathrm{C}$ and the crystallization is almost completed at $160{ }^{\circ} \mathrm{C}$. For the clusters, $T_{\mathrm{x}}$ is close to $180^{\circ} \mathrm{C}$ and the rise in amplitude is more gradual, spanning from $150^{\circ} \mathrm{C}$ up to $200^{\circ} \mathrm{C}$. It has to be observed that the crystallization temperature for the clusters is only $25^{\circ} \mathrm{C}$ above that of the $10 \mathrm{~nm}$ thin film. As already stated, there is no report of $T_{\mathrm{x}}$ values for GST nanoclusters of such small diameter in literature. One can try to compare our results with those reported in Ref. 3 on thin films of various thicknesses, embedded in $\mathrm{Al}_{2} \mathrm{O}_{3}$, which is the same cladding material as used in our work. Strikingly the crystallization temperature obtained for clusters $\left(180^{\circ} \mathrm{C}\right)$ is much less than the value of $340{ }^{\circ} \mathrm{C}$ reported in Ref. 3 for a thin film of $5 \mathrm{~nm}$. Besides, $T_{\mathrm{x}}$ for our $10 \mathrm{~nm}$ thin film $\left(155^{\circ} \mathrm{C}\right)$ is very close to the value

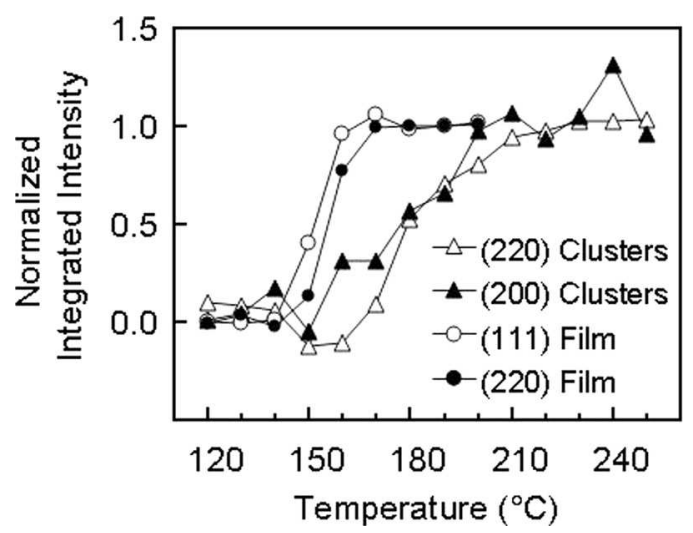

FIG. 3. Normalized integrated intensities for GST clusters (220) and (200), and GST film (111) and (200) diffraction peaks as a function of temperature. reported in Ref. 3 for films with thickness above $10 \mathrm{~nm}$, that is close to that of bulk GST.

The main result of the present work is the observation that even for nanoparticles with a diameter as small as $5 \mathrm{~nm}$ the phase change from the amorphous to the cubic state still takes place. Another important observation is that the out of plane lattice parameter for the crystalline fcc clusters is larger than that of the crystallized $10 \mathrm{~nm}$ thin film, the latter being very close to the lattice parameter measured in bulk fcc cubic GST. Besides, the film $T_{\mathrm{x}}$ is close to the bulk GST value. These two observations suggest a complete relaxation of strain in the $10 \mathrm{~nm}$ thin film cladded with $\mathrm{Al}_{2} \mathrm{O}_{3}$. The increase of the lattice parameter in clusters can be attributed to a large out of plane tensile strain due to the interaction with the oxide matrix. At the phase change, the bulk GST density decreases by $5 \% .{ }^{18}$ While in thin films, the stress resulting from the volume change can be relaxed at crystallization by viscous flow in the amorphous phase, ${ }^{19}$ such a mechanism is less likely to take place in small particles embedded in an oxide matrix. The measured relative out of plane lattice parameter increase in clusters with respect to bulk GST value $(1.7 \%)$ is close to one third of the volume relative change during the amorphous to crystalline phase change. This observation is in favor of an isotropic expansion of clusters and suggests that the volumes of the amorphous and crystalline clusters are similar due to the strong interaction with the embedding alumina, which is a far more rigid material than GST.

As already mentioned, the last important result is the small difference of $T_{\mathrm{x}}$ between clusters and thin films, in contrast with the strong thickness dependence of $T_{\mathrm{x}}$ reported in thin films cladded with $\mathrm{Al}_{2} \mathrm{O}_{3}$. ${ }^{3}$ However, it is hard to compare films and clusters since variations of $T_{\mathrm{x}}$ can result from many factors including different aspects ratio, intrinsic size effects, composition changes, matrix influence, and stress or strain effects. In our case, a possible composition effect could arise since, as compared with the films, the clusters are Te-depleted. For instance, the crystallization temperature in GST thin films with $10 \%-20 \%$ excess $\mathrm{Sb}$ is $15^{\circ} \mathrm{C}$ higher than for bulk films, ${ }^{20}$ and the crystallization temperature for $\mathrm{Ge}_{2} \mathrm{Sb}_{2} \mathrm{Te}_{4}$ is $175^{\circ} \mathrm{C}$. ${ }^{21}$ In order to evaluate the consequences of the strain resulting from the phase change in clusters, it is instructive to evaluate the elastic energy stored in crystallized clusters since it will reduce the driving force for the phase transition. As a consequence, the kinetics for the phase change will be slowed, and during a temperature 
scan, the transition temperature can be increased. In the case of GST, this driving force is $200 \mathrm{MJ} / \mathrm{m}^{3}, 22$ while an order of magnitude calculation for the elastic energy resulting from the strain is closer to $10 \mathrm{MJ} / \mathrm{m}^{3}$, which is not enough to induce significant effects. ${ }^{2}$ Finally, intrinsic size effects could explain the increase of $T_{\mathrm{x}}$ observed in clusters. ${ }^{7}$

In conclusion, we grew nanometric GST clusters by a sputtering gas-aggregation technique, with narrow size distribution around $5.7 \mathrm{~nm}$. Our results demonstrate the possibilities offered by this synthesis technique for the study of well calibrated, isolated or embedded clusters of phase change materials. Moreover, this method is close to other physical techniques used for PCM thin films deposition. The as-grown clusters dispersed in alumina are amorphous and transform into a cubic fcc crystalline phase at a well defined crystallization temperature of $180^{\circ} \mathrm{C}$, which illustrates that the phase change in GST is also present in the sub- $10 \mathrm{~nm}$ range. The crystalline clusters show a lattice parameter larger than that of bulk cubic GST, which indicates a tensile strain that is attributed to the interaction with the alumina matrix. Despite this significant interface coupling, the large increase in $T_{\mathrm{x}}$ observed in very thin GST films subjected to large interface stress is not seen in clusters. These results indicate that the scaling effect on the crystallization temperature in phase change material can be small, which is positive for their application in highly scaled PCRAM devices.

We thank J. F. Bérar (Institut Néel) for his help during the ESRF experimental run and for the X-ray diffraction data analysis. Funding for this work was provided by the RTRA Fondation Nanoscience.

${ }^{1}$ D. Lencer, M. Salinga, and M. Wuttig, Adv. Mater. 23, 2030 (2011).

${ }^{2}$ R. E. Simpson, M. Krbal, P. Fons, A. V. Kolobov, J. Tominaga, T. Uruga, and H. Tanida, Nano Lett. 10, 414 (2010).
${ }^{3}$ S. Raoux, J. Jordan-Sweet, and A. Kellock, J. Appl. Phys. 103, 114310 (2008).

${ }^{4}$ H.-Y. Cheng, S. Raoux, and Y.-C. Chen, J. Appl. Phys. 107, 074308 (2010).

${ }^{5}$ X. Wei, L. Shi, T. C. Chong, R. Zhao, and H. K. Lee, Jpn. J. Appl. Phys., Part 1 46, 2211 (2007).

${ }^{6}$ S. Raoux, H.-Y. Cheng, J. L. Jordan-Sweet, B. Muñoz, and M. Hitzbleck, Appl. Phys. Lett. 94, 183114 (2009).

${ }^{7}$ M. Zacharias and P. Streitenberger, Phys. Rev. B 62, 8391 (2000).

${ }^{8}$ W. D. Nix, Metall. Mater. Trans. A 20, 2217 (1989).

${ }^{9}$ S. Raoux, C. T. Rettner, J. L. Jordan-Sweet, A. J. Kellock, T. Topuria, P. M. Rice, and D. C. Miller, J. Appl. Phys. 102, 094305 (2007).

${ }^{10}$ Y. Zhang, S. Raoux, D. Krebs, L. E. Krupp, T. Topuria, M. A. Caldwell, D. J. Milliron, A. Kellock, P. M. Rice, J. L. Jordan-Sweet, and H.-S. Philip Wong, J. Appl. Phys. 104, 074312 (2008).

${ }^{11}$ H. S. Choi, K. S. Seol, K. Takeuchi, J. Fujita, and Y. Ohki, Jpn. J. Appl. Phys., Part 1 44, 7720 (2005).

${ }^{12}$ H. R. Yoon, W. Jo, E. H. Lee, J. H. Lee, M. Kim, K. Y. Lee, and Y. Khang, J. Non-Cryst. Solids 351, 3430 (2005).

${ }^{13}$ G.-S. Park, J.-H. Kwon, M. Kima, H. R. Yoon, W. Jo, T. K. Kim, J.-M. Zuo, and Y. Khang, J. Appl. Phys. 102, 013524 (2007).

${ }^{14}$ R. Morel, A. Brenac, P. Bayle-Guillemaud, C. Portemont, and F. La Rizza, Eur. Phys. J. D 24, 287 (2003).

${ }^{15}$ H. R. Yoon, W. Jo, E. Cho, S. Yoon, and M. Kim, J. Non-Cryst. Solids 352, 3757 (2006).

${ }^{16}$ S. Kohara, K. Kato, S. Kimura, H. Tanaka, T. Usuki, K. Suzuya, H. Tanaka, Y. Moritomo, T. Matsunaga, N. Yamada, Y. Tanaka, H. Suematsu, and M. Takataa, Appl. Phys. Lett. 89, 201910 (2006).

${ }^{17}$ In our experimental configuration (incident angle equal to $4^{\circ}$ and integration of diffraction rings in a limited angular range), the measured diffracting planes are close to the sample plane. Hence the measured lattice parameter is close to, but not strictly equal to, the out of plane lattice parameter.

${ }^{18}$ T. Nonaka, G. Ohbayashi, Y. Toriumi, Y. Mori, and H. Hashimoto, Thin Solid Films 370, 258 (2000).

${ }^{19}$ T. P. Leervad Pedersen, J. Kalb, W. K. Njoroge, D. Wamwangi, M. Wuttig, and F. Spaepen, Appl. Phys. Lett. 79, 3597 (2001).

${ }^{20}$ K. J. Choi, S. M. Yoon, N. Y. Lee, S. Y. Lee, Y. S. Park, B. G. Yu, and S. O. Ryu, Thin Solid Films 516, 8810 (2008).

${ }^{21}$ M. Wuttig, D. Lüsebrink, D. Wamwangi, W. Welnic, M. Gillessen, and R. Dronskowski, Nature Mater. 6, 122 (2007).

${ }^{22}$ J. A. Kalb, M. Wuttig, and F. Spaepen, J. Mater. Res. 22, 748 (2007).

${ }^{23}$ See supplementary material at http://dx.doi.org/10.1063/1.4769435 for the clusters size distribution and TEM images and the 2D images. 